\title{
Pitch direction on the perception of major and minor modes
}

\author{
Bryan R. Burnham ${ }^{1}$ (D) Emma Long ${ }^{1} \cdot$ Jake Zeide $^{1}$ \\ Accepted: 30 October 2020 / Published online: 23 November 2020 \\ (C) The Psychonomic Society, Inc. 2020
}

\begin{abstract}
One factor affecting the qualia of music perception is the major/minor mode distinction. Major modes are perceived as more arousing, happier, positive, brighter, and less awkward than minor modes. This difference in emotionality of modes is also affected by pitch direction, with ascending pitch associated with positive affect and decreasing pitch with negative affect. The present study examined whether pitch direction influenced the identification of major versus minor musical modes. In six experiments, participants were familiarized with ascending and descending major and minor modes. We then played ascending and descending scales or simple eight-note melodies and asked listeners to identify the mode (major or minor). Identification of mode was moderated by pitch direction: major modes were identified more accurately when played with ascending pitch, and minor modes were identified better when played with descending pitch. Additionally, we replicated the difference in emotional affect between major and minor modes. The crossover pattern in mode identification may result from dual activation of positive and negative constructs, under specific combinations of mode and pitch direction.
\end{abstract}

Keywords Music perception $\cdot$ Musical mode $\cdot$ Pitch direction

Previous studies have examined the role that musical structure, such as tempo (fast versus slow), mode (major versus minor), consonance/dissonance, and pitch direction (ascending versus descending), has on tone discrimination, perceived emotional valence and arousal, memory, and spatial reasoning (e.g., Battcock \& Schultz, 2019; Collier \& Hubbard, 2001, 2004; Crowder, 1984, 1985; Egmond \& Boswijk, 2007; Friedman, Neill, Seror, \& Kleinsmith, 2018; Heinlein, 1928; Husain, Thompson, \& Schellenberg, 2002; Johnson-Laird, Kang, \& Leong, 2012; Justus, Gabriel, \& Pfaff, 2018; Kleinsmith, Friedman, \& Neill, 2017; McLachlan, Marco, Light, \& Wilson, 2013; Mead \& Ball, 2007; Sollberger, Reber, \& Eckstein, 2003; Thompson \& Cuddy, 1997). Of relevance to the present study are the influences that mode (major/minor) and pitch direction (ascending/descending) have on mode identification. Studies consistently show that major modes (e.g., C-Maj, F-Maj) are perceived more positive and arousing than minor modes (a-min, d-min; Collier \& Hubbard, 2001, 2004; Crowder, 1984, 1985; Justus et al., 2018; Parncutt, 2014), and higher, ascending pitches are

Bryan R. Burnham

attention.perform@gmail.com

1 Department of Psychology, The University of Scranton, Scranton, PA 18510, USA perceived as happier and more arousing than lower, descending pitches (Collier \& Hubbard, 2001, 2004; Friedman et al., 2018). The present study examined the interactive influence of mode and pitch direction on the identification of major and minor modes.

The finding that major musical modes ${ }^{1}$ are perceived as more positive, whereas minor modes are perceived as more negative, can be traced to early studies on music perception. Heinlein (1928; discussed and reanalyzed by Crowder, 1984) played major and minor chords to subjects who were musically trained or novices. Using a checklist of emotional adjectives, listeners tended to select negative terms to describe minor chords and positive terms for major chords. Similarly, Hevner (1935) played musical pieces in a major mode or its relative minor (minor with the same key signature as a major key). Like Heinlein (1928), listeners selected emotional adjectives from a checklist to describe their feelings toward each piece, and like Heinlein (1928), listeners tended to select negative adjectives for pieces played in minor keys and selected positive adjectives for pieces played in major keys.

\footnotetext{
${ }^{1}$ A major mode includes a scale (series of eight ascending or descending notes) where the third and fourth intervals and the seventh and eighth intervals are separated by a semitone, with all other intervals separated by a whole tone. Every major scale has a relative minor with the same key signature but built on the sixth degree (sixth note) of the major scale. In a minor scale, the second and third intervals and the fifth and sixth intervals are separated by a semitone, with all other intervals separated by a whole tone.
} 
Affective evaluation of music as a function of mode shows a developmental progression, suggesting the connection between mode and emotionality is learned (Parncutt, 2014). For example, Gerardi and Gerken (1995) presented major and minor melodies that ascended or descended in pitch to 5-year-olds, 8 -year-olds, and college students. Both 8-year-olds and college students perceived major melodies as happier than minor melodies, whereas 5-year-olds exhibited no difference in affective judgments. Similarly, Dalla Bella, Peretz, Rousseau, and Gosselin (2001) presented classical music excerpts (e.g., 'Brindisi' from Verdi's Traviata; Albinoni's Adagio), with each piece played in its original form or with its tempo or mode changed. Like Gerardi and Gerken (1995), Dalla Bella et al. (2001) found that adults and 6-to-8-year-olds were influenced by mode in their affective judgments, but 5 -year-olds were not. These and other studies (e.g., Gregory, Worrall, \& Sarge, 1996; Trehub, 1993) suggest a gradual development of the connection between mode and emotion. (But see Kastner \& Crowder, 1990, for a demonstration that children as young as 3 years show affective responses to mode.)

In a pair of studies, Collier and Hubbard (2001, 2004) examined the influence of mode, pitch, and scale direction on evaluations of happiness, awkwardness, and brightness. Listeners evaluated the aesthetic qualities of eight-note musical scales (ascending and descending natural minor scales, harmonic minor scales, melodic minor scales, and major scales) on 7-point Likert scales. Both studies found that ascending minor scales were rated as more positive (happier, brighter), but also rated as more awkward than descending minor scales. Additionally, ascending major scales were rated as happier and brighter than descending major scales, with no difference in awkwardness. Although they did not compare aesthetic ratings of major and minor modes directly, an examination of Collier and Hubbard's $(2001,2004)$ results suggest major scales were rated as happier, brighter, and less awkward than all minor scales. Given these results, this suggests a relationship between pitch direction and mode on the emotional evaluation of musical scales.

Studies have revealed that major and minor modes are perceived categorically. Zatorre and Halpern (1979; see also Blechner, 1977; Burns \& Ward, 1982; Crowder, 1985) presented musical dyads where the bottom note was constant $(\mathrm{F}$; $349 \mathrm{~Hz}$ ), but the top note varied in equal steps from $\mathrm{Ab}$ (415 $\mathrm{Hz})$ to $\mathrm{A}(440 \mathrm{~Hz})$, such that the interval ranged from a true minor third to a true major third. Zatorre and Halpern (1979) found that listeners tended to identify smaller intervals as distinctly 'minor' and larger intervals as distinctly 'major'; hence, there was a clear boundary between what was perceived as minor and major. Similar results were obtained by Crowder (1985) and Blechner (1977) using triads that ranged between minor chords and major chords, suggesting major modes are perceived as qualitatively different from minor modes.
Given the abundance of research showing major and minor modes are perceived categorically and emotionally different and that pitch direction influences the evaluation of mode, the present study examined whether pitch direction influenced the identification of major and minor modes. Specifically, will the direction of pitch (ascending or descending) facilitate or interfere with a listener's ability to identify a piece of music as major or minor. To examine the possible interaction between mode and pitch direction, we presented ascending and descending scales (Experiments 2) or simple melodies (Experiments 3, 4, 5 ) in major and minor modes, and asked subjects to identify whether each scale or melody was 'major' or 'minor' as accurately as possible. Because we recruited subjects through undergraduate Introduction to Psychology courses, we did not assume extensive music training. As such, in each experiment subjects were first presented with examples of major and minor scales in ascending and descending pitch to become familiarized with the two modes. We expected to replicate previous research showing that major modes and ascending pitch are perceived more positively (happier, brighter, less awkward) than minor modes and descending pitch. Additionally, and importantly, we expected pitch direction to influence listeners to identify major and minor modes.

\section{Experiment 1}

The purpose of Experiment 1 was to ensure that our participant pool perceived major and minor modes differently. We replicated the procedures and analyses from Collier and Hubbard $(2001,2004)$ and attempted to observe their findings that major scales and ascending scales are perceived as happier, less awkward, and brighter than minor scales and descending scales. We also examined a possible interaction between pitch direction (ascending or descending) and mode on happiness, awkwardness, and brightness ratings. Listeners were presented with a scale (ascending or descending; major, natural minor, or harmonic minor) and rated how awkward, bright, or happy the scale sounded.

\section{Methods}

\section{Subjects}

Fifteen undergraduate students from the University of Scranton participated (12 females, 15 right-handed) and received credit toward completion of a research requirement. Subjects ranged in age from 18 to 20 years $(M=18.47, S D$ $=0.64$ ), and all reported normal or corrected-to-normal hearing. Subjects were also given a questionnaire to gain an understanding of their musical background. 


\section{Stimuli and apparatus}

Experiments were programmed using E-Prime software (Version 2.0.10.356) on a Dell Optiplex 3050 x64 computer. Displays were presented on a Dell E178Fpv monitor where the background was always white with letters in black Courier font. Subjects wore SONY Sound Isolating Headphones to listen to the scales. Each musical scale was made up of eight quarter notes, played at a tempo of 90 beats per minute (BPM). Musical scales (and melodies in Experiments 3-5, and chromatic scales in Experiment 6) were created using MuseScore (Version 2.0.3) software, using a grand piano sound. The keys used for the major scales included C-Maj, Bb-Maj, Ab-Maj, D-Maj, E-Maj, and F\#-Maj. Both the natural minor and harmonic minor keys were the relative minors for the major keys, and included: a-min, b-min, c\#-min, d\#min, f-min, and g-min. Each of these 18 scales was rated three times, once each for happiness, awkwardness, and brightness. Participants completed one block consisting of 108 trials, which was preceded by a practice block of five trials that were not analyzed.

\section{Procedures}

Participants entered the room and were greeted by a research assistant. After being seated at a computer, subjects were asked to fill out a consent form and music background questionnaire. The questionnaire asked whether participants had any formal music training, had ever taken private music lessons, played any musical instruments or performed vocal music, and for each "yes" response were asked for how many years they had done so.

Participants were handed headphones to put on after being read the written instructions from the computer monitor prior to the experiment. Participants initiated each trial by pressing the space bar. A scale was played, and subjects were told to listen and then rate the scale on how (1) awkward the scale sounded, (2) how bright/dark the scale sounded, or how sad/ happy the scale sounded. All ratings were made on a 7-point scale using the keyboard to respond. The selection of scale, direction, and what quality subjects were asked to rate was randomized.

\section{Results}

Several analyses were carried out on the ratings. First, we examined whether Collier and Hubbard's $(2001,2004)$ results were replicated by conducting the same analyses, separately on minor scales and major scales (collapsed across keys). All planned comparisons are the same as those performed by Collier and Hubbard $(2001,2004)$. Next, we examined whether mode and pitch direction interacted in their influence on the ratings.
Happiness

Minor scales A repeated-measures analysis of variance (ANOVA) revealed a difference in happiness across ascending and descending natural minor and harmonic minor modes, $F(3,42)=12.50, M S E=0.290, p<.001, \eta_{\mathrm{p}}{ }^{2}=0.47$. Ascending minor scales, collapsed over natural and harmonic styles, were happier $(M=3.83, S D=0.88)$ than descending minor scales $(M=3.17, S D=0.92), t(14)=4.75, S E=0.14, p$ $<.001, d=0.72$. Natural minor scales were rated as happier $(M=3.77, S D=0.91)$ than harmonic minor scales $(M=3.23$, $S D=0.92), t(14)=3.78, S E=0.16, p=.005, d=0.58$. Ascending natural minor scales $(M=4.14, S D=1.01)$ were rated as happier than descending natural minor scales $(M=$ 3.39, $S D=0.94), t(14)=4.37, S E=0.17, p=.001, d=0.78$; likewise for ascending harmonic minor scales $(M=3.51, S D=$ 1.05) than for descending harmonic minor scales $(M=2.96$, $S D=0.93), t(14)=2.92, S E=0.19, p=.011, d=0.56$. Unlike in Collier and Hubbard (2001), ascending natural minor scales were rated as happier (not sadder) than ascending harmonic minor scales, $t(14)=2.35, S E=0.27, p=.034, d=0.62$; and descending natural minor scales were rated as happier (not sadder) than descending harmonic minor scales, $t(14)=$ 5.99, $S E=0.07, p<.001, d=0.46$.

Major scales Ascending major scales $(M=5.24, S D=1.00)$ were rated as happier than descending major scales $(M=4.07$, $S D=0.78), t(14)=4.56, S E=0.26, p<.001, d=1.31$.

\section{Awkwardness}

Minor scales A repeated-measures ANOVA revealed a nonsignificant difference in awkwardness ratings across ascending and descending natural minor and harmonic minor scales, $F(3,42)=2.20, M S E=0.670, p=.102, \eta_{\mathrm{p}}{ }^{2}=0.14$. Although this did not replicate Collier and Hubbard (2001), who observed a significant difference, the same comparisons were conducted. The difference between ascending minor scales $(M=4.02, S D=1.27)$ and descending minor scales $(M=$ $3.74, S D=1.13$ ) was not statistically significant, $t(14)=$ 1.37, $S E=0.20, p=.193, d=0.23$. Harmonic minor scales were rated as more awkward $(M=4.09, S D=1.20)$ than natural minor scales $(M=3.67, S D=1.25), t(14)=1.71, S E$ $=0.25, p=.109, d=0.34$. There was no difference in awkwardness between ascending $(M=3.71, S D=1.44)$ and descending natural minor scales $(M=3.63, S D=1.34), t<1, d=$ 0.06 . The difference between ascending harmonic minor scales $(M=4.33, S D=1.38)$ and descending harmonic minor scales $(M=3.86, S D=1.17)$ was not significant, $t(14)=2.12$, $S E=0.22, p=.052, d=0.37$, nor was the difference between ascending harmonic minor scales and ascending natural minor scales, $t(14)=1.95, S E=0.32, p=.072, d=0.44$. There was 
no difference in awkwardness between the descending natural minor and harmonic minor scales $(t<1, d=0.18)$.

Major scales Descending major scales $(M=3.00, S D=1.40)$ were rated as more awkward than ascending major scales $(M=$ 2.24, $S D=1.21), t(14)=3.05, S E=0.25, p=.009, d=0.58$.

\section{Darkness}

Minor scales A repeated-measures ANOVA revealed that brightness ratings differed across ascending and descending natural minor and harmonic minor scales, $F(3,42)=7.26, M S E=$ $0.316, p<.001, \eta_{\mathrm{p}}{ }^{2}=0.341$. Ascending minor scales $(M=4.08$, $S D=0.98)$ were brighter than descending scales $(M=3.50, S D=$ $0.93), t(14)=3.90, S E=0.15, p=.002, d=0.60$; and natural minor scales were rated as brighter $(M=3.97, S D=0.95)$ than harmonic minor scales $(M=3.61, S D=0.91), t(14)=3.38, S E=$ $0.11, p=.004, d=0.39$. Ascending natural minor scales $(M=$ $4.24, S D=1.12$ ) were rated as brighter than descending scales $(M=3.70, S D=0.92), t(14)=2.78, S E=0.20, p=.015, d=$ 0.53 ; and ascending harmonic minor scales $(M=3.91, S D=$ 1.05) were rated as brighter than the descending scales $(M=$ $3.31, S D=1.03), t(14)=2.35, S E=0.26, p=.034, d=0.58$. The difference between ascending natural minor scales and ascending harmonic minor scales was not significant, $t(14)=1.37$, $S E=0.24, p=.193, d=0.31$; and descending natural minor scales were rated as brighter than descending harmonic minor scales, $t(14)=2.52, S E=0.15, p=.024, d=0.40$.

Major scales Ascending major scales $(M=5.30, S D=0.99)$ were rated as brighter than descending major scales $(M=4.29$, $S D=0.91), t(14)=6.806, S E=0.15, p<.001, d=1.06$.

\section{Across-mode analyses}

Having replicated the general pattern of results reported by Collier and Hubbard $(2001,2004)$, we examined the influence of mode and pitch direction on the happiness, awkwardness, and brightness ratings. For the analyses that follow, we included only the natural minor scales, which were used in Experiments 2-5. The results of 2 (mode: major vs. minor) $\times 2$ (direction: ascending vs. descending) repeated-measures ANOVAs on the ratings are reported in Table 4 in Appendix 1 and mean ratings are reported in Table 1 . The sections below describe the patterns of results based on the ANOVAs.

Happiness Major modes $(M=4.65)$ were rated as happier than natural minor modes $(M=3.77)$, as were ascending scales $(M$ $=4.69)$ compared with descending scales $(M=3.73)$. Though the difference in happiness ratings between major and minor modes was larger for ascending scales $\left(M_{\text {diff }}=1.18 ; 95 \%\right.$ CI $[0.62,1.73])$ than descending scales $\left(M_{\text {diff }}=0.76 ;[0.38\right.$, $1.13])$, the interaction was not significant; an additive effect
Table 1 Means (and $S D$ ) or the aesthetic ratings to ascending and descending major and natural minor Scales in Experiments 1-5, and to ascending and descending chromatic scales in Experiment 6

\begin{tabular}{|c|c|c|c|c|c|c|c|}
\hline \multirow[t]{3}{*}{ Exp. } & \multirow[t]{3}{*}{$N$} & \multirow[t]{3}{*}{ Measure (Scale) } & \multirow[t]{3}{*}{ Direction } & \multicolumn{4}{|c|}{ Musical mode } \\
\hline & & & & \multicolumn{2}{|c|}{ Major } & \multicolumn{2}{|c|}{ Natural minor } \\
\hline & & & & $M$ & $S D$ & $M$ & $S D$ \\
\hline \multirow[t]{6}{*}{1} & \multirow[t]{6}{*}{15} & \multirow[t]{2}{*}{ Sad/Happy (1-7) } & Ascending & 5.24 & 1.00 & 4.14 & 1.01 \\
\hline & & & Descending & 4.07 & 0.78 & 3.39 & 0.94 \\
\hline & & \multirow[t]{2}{*}{ Awkward (1-7) } & Ascending & 2.24 & 1.21 & 3.71 & 1.44 \\
\hline & & & Descending & 3.00 & 1.40 & 3.63 & 1.34 \\
\hline & & \multirow[t]{2}{*}{ Brightness (1-7) } & Ascending & 5.30 & 0.99 & 4.24 & 1.12 \\
\hline & & & Descending & 4.29 & 0.91 & 3.70 & 0.92 \\
\hline \multirow[t]{4}{*}{2} & \multirow[t]{4}{*}{20} & \multirow[t]{2}{*}{ Sad/Happy (1-7) } & Ascending & 5.06 & 0.74 & 3.68 & 0.94 \\
\hline & & & Descending & 3.87 & 0.69 & 2.81 & 0.78 \\
\hline & & \multirow[t]{2}{*}{ Awkward (1-7) } & Ascending & 2.98 & 0.85 & 3.50 & 0.98 \\
\hline & & & Descending & 2.80 & 1.02 & 4.02 & 1.12 \\
\hline \multirow[t]{4}{*}{3} & \multirow[t]{4}{*}{20} & \multirow[t]{2}{*}{ Sad/Happy (1-7) } & Ascending & 5.14 & 0.84 & 4.08 & 1.18 \\
\hline & & & Descending & 3.88 & 1.14 & 2.89 & 0.94 \\
\hline & & \multirow[t]{2}{*}{ Awkward (1-7) } & Ascending & 3.22 & 1.42 & 4.44 & 0.96 \\
\hline & & & Descending & 2.98 & 1.62 & 3.92 & 1.05 \\
\hline \multirow[t]{4}{*}{4} & \multirow[t]{4}{*}{20} & \multirow[t]{2}{*}{ Sad/Happy (1-7) } & Ascending & 4.73 & 1.04 & 3.91 & 0.72 \\
\hline & & & Descending & 3.56 & 0.89 & 2.98 & 0.79 \\
\hline & & \multirow[t]{2}{*}{ Awkward (1-7) } & Ascending & 3.17 & 0.92 & 3.83 & 0.97 \\
\hline & & & Descending & 2.67 & 1.03 & 3.70 & 0.91 \\
\hline \multirow[t]{6}{*}{5} & \multirow[t]{6}{*}{19} & \multirow[t]{2}{*}{ Sad/Happy (1-7) } & Ascending & 4.97 & 1.05 & 4.57 & 0.89 \\
\hline & & & Descending & 3.55 & 0.88 & 3.09 & 0.82 \\
\hline & & \multirow[t]{4}{*}{ Awkward (1-7) } & Ascending & 2.78 & 1.28 & 3.82 & 1.22 \\
\hline & & & Descending & 2.56 & 1.20 & 3.57 & 1.39 \\
\hline & & & & \multicolumn{2}{|c|}{ Chromatic } & & \\
\hline & & & & $M$ & $S D$ & & \\
\hline 6 & 20 & Sad/Happy (1-7) & Ascending & 4.55 & 0.60 & & \\
\hline & & & Descending & 2.92 & 0.69 & & \\
\hline & & Awkward (1-7) & Ascending & 3.13 & 0.96 & & \\
\hline & & & Descending & 3.34 & 1.00 & & \\
\hline & & Brightness (1-7) & Ascending & 4.78 & 0.62 & & \\
\hline & & & Descending & 3.20 & 0.91 & & \\
\hline
\end{tabular}

that replicates happiness ratings of ascending and descending major and minor melodies observed by Lee, Janata, Frost, Hanke, and Granger (2011).

Awkwardness Major modes $(M=2.62)$ were rated as less awkward than minor modes $(M=3.67)$. The difference between ascending scales $(M=2.98)$ and descending scales $(M=$ 3.32) was not significant. The interaction revealed a difference in awkwardness between ascending major and minor scales $\left(M_{\text {diff }}=0.76 ;[0.22,1.29]\right)$, but not descending scales $\left(M_{\text {diff }}=\right.$ $0.08 ;[-0.59,0.74])$.

Brightness Major modes $(M=4.79)$ were rated as brighter than minor modes $(M=3.97)$, as were ascending scales $(M$ 
$=4.77)$ compared with descending scales $(M=3.99)$. The interaction revealed a larger difference in brightness ratings between ascending major and minor modes $\left(M_{\text {diff }}=1.01\right.$; $[0.69,1.33])$ than descending major and minor modes $\left(M_{\text {diff }}\right.$ $=0.54 ;[0.12,0.96])$.

\section{Discussion}

Experiment 1 generally replicated the pattern of results observed by Collier and Hubbard (2001, 2004): Major modes were perceived more positively than minor modes (i.e., happier, brighter, less awkward), and ascending scales were perceived more positively than descending scales. Although the mode-by-direction interaction was statistically significant only for the awkwardness ratings, the overall pattern of results in Experiment 1 suggests that pitch direction influences the perception of mode. In the following experiments, we examined whether pitch direction influenced a listener's ability to identify major versus minor modes.

\section{Experiment 2}

We examined whether pitch direction affected identification of major and minor modes. During a training phase, listeners were presented with an ascending and descending major scale (C-Maj) and an ascending and descending minor scale (a$\mathrm{min}$ ), to become familiarized with the major and minor modes. During a test phase, listeners were presented with major and natural minor scales that ascended or descended in pitch and were asked to identify as accurately as possible whether the scale was major or minor; hence, we examined the influence of pitch direction on identification of major and minor modes. Last, during a rating phase, subjects rated how happy and how awkward each scale sounded.

\section{Methods}

Unless described below, all methods were the same as in Experiment 1.

\section{Subjects}

Twenty undergraduate students participated (18 females, 18 right-handed). Subjects ranged in age from 18 to 20 years $(M$ $=18.30, S D=0.57$ ) and reported normal or corrected-tonormal hearing.

\section{Stimuli and apparatus}

The C-Maj and a-natural minor scales were used during the training phase (described below). During the test phase, all major scales (except C-Maj) were presented (A, Ab, B, Bb,
$\mathrm{CH}, \mathrm{D}, \mathrm{Eb}, \mathrm{E}, \mathrm{F}, \mathrm{F} \#, \mathrm{G})$ in both ascending and descending pitch, and all natural minor scales (except a-min) were presented (ab, b, bb, c, c\#, d, d\#, e, f, f\#, g) in both ascending and descending pitch. In this testing phase, listeners completed one block of 44 trials with each of the 22 scales presented twice (once ascending and once descending). During the rating phase, all major scales (except C-Maj) and all minor scales (except a-min) from the test phase were presented. Participants completed one block of rating 88 trials, with each of the 22 scales presented twice ascending and twice descending, and each being rated once for awkwardness and once for happiness.

\section{Procedures}

The training phase was performed to familiarize listeners with major and minor modes. The C-Maj and a-min scales were played 10 times ascending and then 10 times descending, with the screen informing listeners what mode they were hearing and whether the scale was ascending or descending. The order of this major or minor "ear training" phase was counterbalanced between subjects. During the testing phase, participants listened to a scale and identified the scale as major or minor. Subjects pressed the $m$ key for major and the $z$ key for minor. Then, a different screen was displayed asking participants to rate their confidence on a scale from 1 (not at all confident) to 7 (completely confident). Finally, the rating phase consisted of rating the happiness and awkwardness of the scale. The order of mode and direction was randomized within all blocks.

\section{Results}

Although participants were asked to rate their confidence in identifying each, these data were not analyzed, as over $50 \%$ of the ratings were 6 or 7 , with few ratings being a 1 or $2(<4 \%)$. As such, any analyses would be biased. This trend toward selecting high confidence ratings was seen in Experiments $3-5$; hence, the confidence ratings are not considered further.

\section{Accuracy}

For each subject, the proportion of correctly identified major scales and minor scales was determined for ascending and descending versions of the scales. Mean proportions correct appear in Fig. 1. A 2 (mode: major vs. minor) $\times 2$ (direction: ascending vs. descending) repeated-measures ANOVA revealed a nonsignificant effect of direction, $F(1,19)=3.97$, $M S E=0.016, p=.061, \eta_{\mathrm{p}}{ }^{2}=0.17 ; M_{\text {Ascending }}=0.70 ;[0.60$, $0.81] ; M_{\text {Descending }}=0.65 ;[0.55,0.75]$. The main effect of mode was nonsignificant $\left(F=2.40, p=.138, \eta_{\mathrm{p}}{ }^{2}=0.11\right)$; however, the interaction was significant, $F(1,19)=6.68$, $M S E=0.054, p=.018, \eta_{\mathrm{p}}{ }^{2}=0.26$. The difference in accuracy between ascending and descending major modes was 
- - - Major

Experiment 2

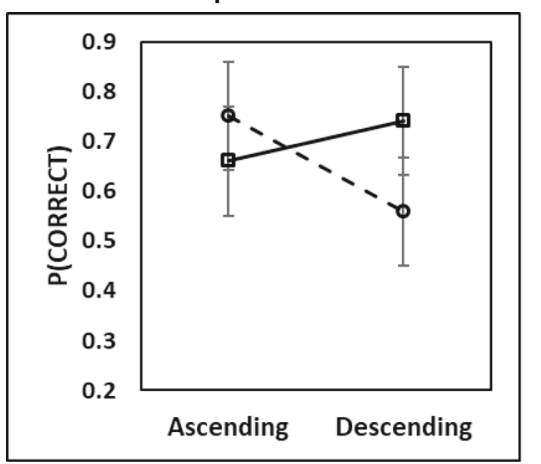

Experiment 4

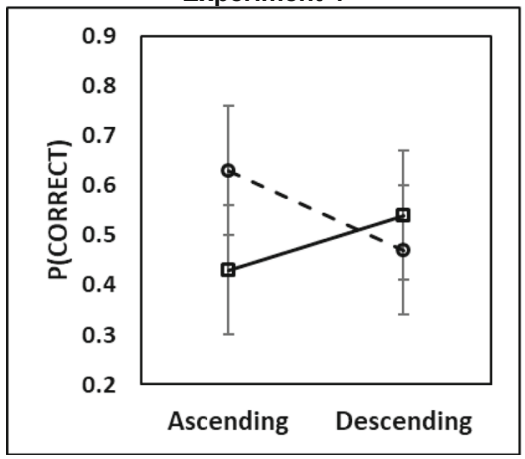

Fig. 1 Mean proportions correct to identify the musical mode (major and minor) of scales (Experiment 2) and melodies (Experiments 3-5) as a function of ascending versus descending pitch. Error bars are the 95\%

nonsignificant $\left(M_{\text {diff }}=0.09 ;[-0.02,0.21]\right), t(19)=1.65, S E=$ $0.055, p=.113$, whereas the difference in accuracy between ascending and descending minor modes was significant $\left(M_{\text {diff }}\right.$ $=0.18 ;[0.05,0.31]), t(19)=2.81, S E=0.063, p=.011$.

\section{Emotional ratings}

Results of 2 (mode: major vs. minor) x 2 (direction: ascending vs. descending) repeated-measures ANOVAs are reported in Table 4 in Appendix 1, with mean ratings reported in Table 1.

Happiness Major modes $(M=4.47)$ were rated as happier than minor modes $(M=3.24)$, as were ascending scales $(M=4.37)$ compared with descending scales $(M=3.34)$. The interaction was not significant, and the pattern differed from Experiment 1. Specifically, the difference in happiness between major and minor was larger for ascending scales $\left(M_{\text {diff }}=1.38 ;[0.80\right.$, 1.97]) than for descending scales $\left(M_{\text {diff }}=1.06 ;[0.50,1.61]\right)$.

Awkwardness Major modes $(M=2.89)$ were rated as less awkward than minor modes $(M=3.76)$, but the difference in awkwardness between ascending scales $(M=3.24)$ and descending scales $(M=3.41)$ was not significant. The interaction revealed a larger difference in awkwardness between
巴 Minor

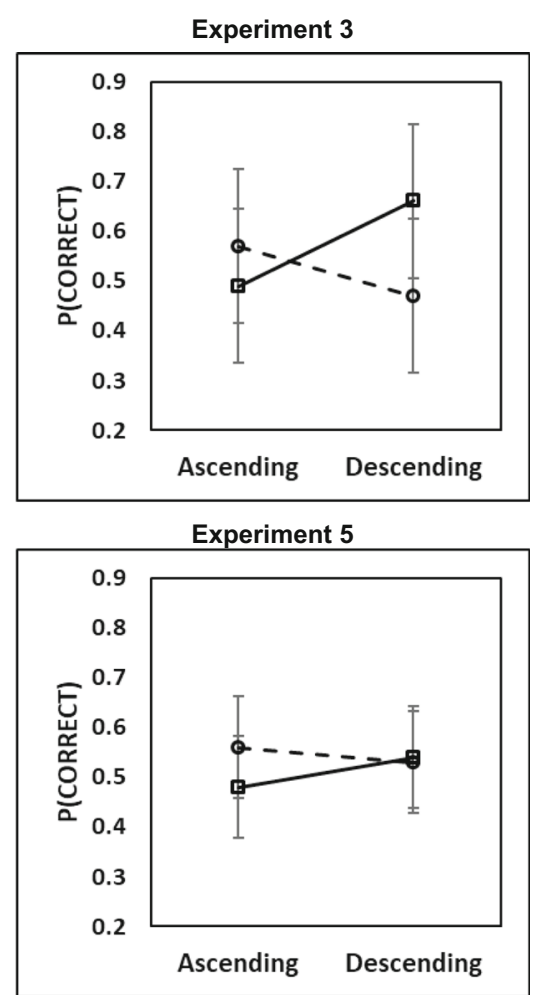

confidence intervals based on the within-subjects error term (Equation 2, Hollands \& Jarmasz, 2010)

descending major and minor modes $\left(M_{\text {diff }}=1.22 ;[0.69\right.$, $1.74])$ than for ascending modes $\left(M_{\text {diff }}=0.52 ;[0.10,0.94]\right)$.

\section{Sensitivity and response bias}

The interaction in the accuracy analyses suggests pitch direction influenced perception of mode. To examine whether pitch direction influenced sensitivity to identify mode or response bias toward selecting modes, an exploratory analysis based on signal detection theory (SDT) was performed (Green \& Swets, 1966; Macmillan \& Creelman, 2005). Our design did not include stimulus-present and stimulus-absent conditions (scale was presented on each trial); as such, based on Macmillan and Creelman (2005), we chose 'major' to represent the stimulus present condition and stimulus present response. Thus, a hit was defined as a listener correctly selecting 'major' when a major scale was played, and a false alarm occurred when a minor scale was played and a listener selected 'major' as the response. ${ }^{2}$

\footnotetext{
${ }^{2}$ The SDT analysis could be conducted with 'minor' used as the stimuluspresent condition and response. In this case, the SDT measures $\left(d^{\prime}\right.$ and c) would be the same values as those reported here, but would be switched between the ascending and descending pitch conditions. Additionally, the statistical outcomes would be the same, but the interpretations would be adjusted to reflect sensitivity and response bias toward identifying minor modes, rather than toward major modes, as in the analyses reported here.
} 
For each subject, the proportions of hits and false alarms were determined for ascending and descending scales (see Table 2). These values were $z$ transformed, which were used to calculate the SDT measures. Sensitivity was measured using $d^{\prime}$, where $d^{\prime}=z(\mathrm{Hit})-z(\mathrm{FA})$. Response bias was measured using $\mathrm{c}$, where $\mathrm{c}=-1 / 2[z(\mathrm{Hit})+z(\mathrm{FA})]$. Because 'major' was treated as the stimulus-present condition and response, larger values of $d^{\prime}$ reflect greater sensitivity identifying major modes. Additionally, because $\mathrm{c}=0$ reflects unbiased responding, negative values of $\mathrm{c}$ reflect a bias toward selecting 'major' and positive values of $\mathrm{c}$ reflect a bias toward selecting 'minor' (bias against selecting major).

The average $d^{\prime}$ ' and c values for ascending and descending scales appear in Table 2 along with the results of pairedsamples $t$ tests comparing ascending and descending SDT measures. Sensitivity $\left(d^{\prime}\right)$ was numerically larger for ascending scales than for descending scales, but this difference was marginally nonsignificant $(p=.059)$. The difference in $\mathrm{c}$ between ascending and descending scales was significant $(p=$ .026) and reflects bias toward selecting 'major' for ascending scales and a bias toward selecting 'minor' for descending scales.

\section{Discussion}

Analyses of the emotional ratings largely replicated those observed in Experiment 1; specifically, major modes were perceived more positively than minor modes, and ascending scales were perceived more positively than descending scales. The novel and more important result was the interaction between mode and pitch direction for mode identification. Major modes were easier (though nonsignificantly) to identify when ascending, and minor modes were easier to identify when descending. This crossover interaction suggests ascending pitch may enhance the perceptibility of major modes while impeding the perceptibility of minor modes. At the same time, descending pitch may enhance the perceptibility of minor modes while impeding the perception of major modes. However, the exploratory SDT analyses suggests this interaction between mode and direction may affect the response bias toward selecting modes, a point we will address in the General Discussion.

\section{Experiment 3}

Experiment 2 established that identification of mode was affected by pitch direction, and we next sought to extend this to melodies. The procedures used in Experiment 3 were the same as Experiment 2; the only difference was in the testing phase, where subjects listened to simple eight-note melodies (see Table 3). For each melody, the first four notes were indistinguishable as belonging to a major or minor mode, while the final four notes revealed (a) the melody as major or minor and

Table 2 Results of signal detection theory analyses on listeners' abilities to distinguish major modes from minor modes in Experiments 2-5

\begin{tabular}{|c|c|c|c|c|c|c|c|c|c|}
\hline \multirow[t]{2}{*}{ Exp. } & \multirow[t]{2}{*}{ Measure } & \multicolumn{2}{|c|}{ Ascending pitch } & \multicolumn{2}{|c|}{ Descending pitch } & \multicolumn{4}{|c|}{ Ascending - Descending } \\
\hline & & $M$ & $S D$ & $M$ & $S D$ & $t$ & $S E$ & $p_{\text {(two-tailed) }}$ & Cohen's $d$ \\
\hline \multirow[t]{4}{*}{2} & $\mathrm{P}(\mathrm{Hit})$ & 0.74 & 0.20 & 0.55 & 0.29 & & & & \\
\hline & $\mathrm{P}(\mathrm{FA})$ & 0.35 & 0.28 & 0.27 & 0.20 & & & & \\
\hline & $d^{\prime}$ & 1.88 & 2.13 & 1.33 & 1.98 & 2.01 & 0.27 & .059 & 0.26 \\
\hline & $\mathrm{c}$ & -0.28 & 0.78 & 0.52 & 0.88 & -2.42 & 0.33 & .026 & -0.95 \\
\hline \multirow[t]{4}{*}{3} & $\mathrm{P}(\mathrm{Hit})$ & 0.57 & 0.21 & 0.47 & 0.22 & & & & \\
\hline & $\mathrm{P}(\mathrm{FA})$ & 0.51 & 0.20 & 0.34 & 0.20 & & & & \\
\hline & $d^{\prime}$ & 0.30 & 1.05 & 0.63 & 1.27 & -1.82 & 0.18 & .084 & -0.28 \\
\hline & $\mathrm{c}$ & -0.29 & 1.03 & 0.60 & 1.06 & -1.99 & 0.45 & .061 & -0.85 \\
\hline \multirow[t]{4}{*}{4} & $\mathrm{P}(\mathrm{Hit})$ & 0.64 & 0.17 & 0.47 & 0.16 & & & & \\
\hline & $\mathrm{P}(\mathrm{FA})$ & 0.57 & 0.18 & 0.45 & 0.16 & & & & \\
\hline & $d^{\prime}$ & 0.26 & 0.40 & 0.08 & 0.64 & 1.30 & 0.14 & .209 & 0.33 \\
\hline & $\mathrm{c}$ & -0.68 & 1.24 & 0.22 & 0.73 & -2.16 & 0.42 & .045 & -0.88 \\
\hline \multirow[t]{4}{*}{5} & $\mathrm{P}(\mathrm{Hit})$ & 0.56 & 0.16 & 0.53 & 0.46 & & & & \\
\hline & $\mathrm{P}(\mathrm{FA})$ & 0.52 & 0.11 & 0.14 & 0.14 & & & & \\
\hline & $d^{\prime}$ & 0.16 & 0.50 & 0.24 & 0.44 & -0.69 & 0.11 & .502 & -0.16 \\
\hline & $\mathrm{c}$ & -0.22 & 0.65 & 0.02 & 0.71 & -0.86 & 0.27 & .399 & -0.34 \\
\hline
\end{tabular}

Note. The mean proportions of hits and false alarms are for reference and were not analyzed. The paired-samples $t$ tests on the SDT measures $\left(d^{\prime}\right.$ and c) were conducted by subtracting the descending $d^{\prime}$ ' and $\mathrm{c}$ values from the ascending values. Larger values of $d^{\prime}$ ' indicate greater sensitivity in distinguishing major from minor modes. Negative values of $\mathrm{c}$ indicate bias toward responding 'major' and positive values of $\mathrm{c}$ indicate bias responding 'minor' 
Table 3 Examples of the eight-note melodies used in Experiments 3-5

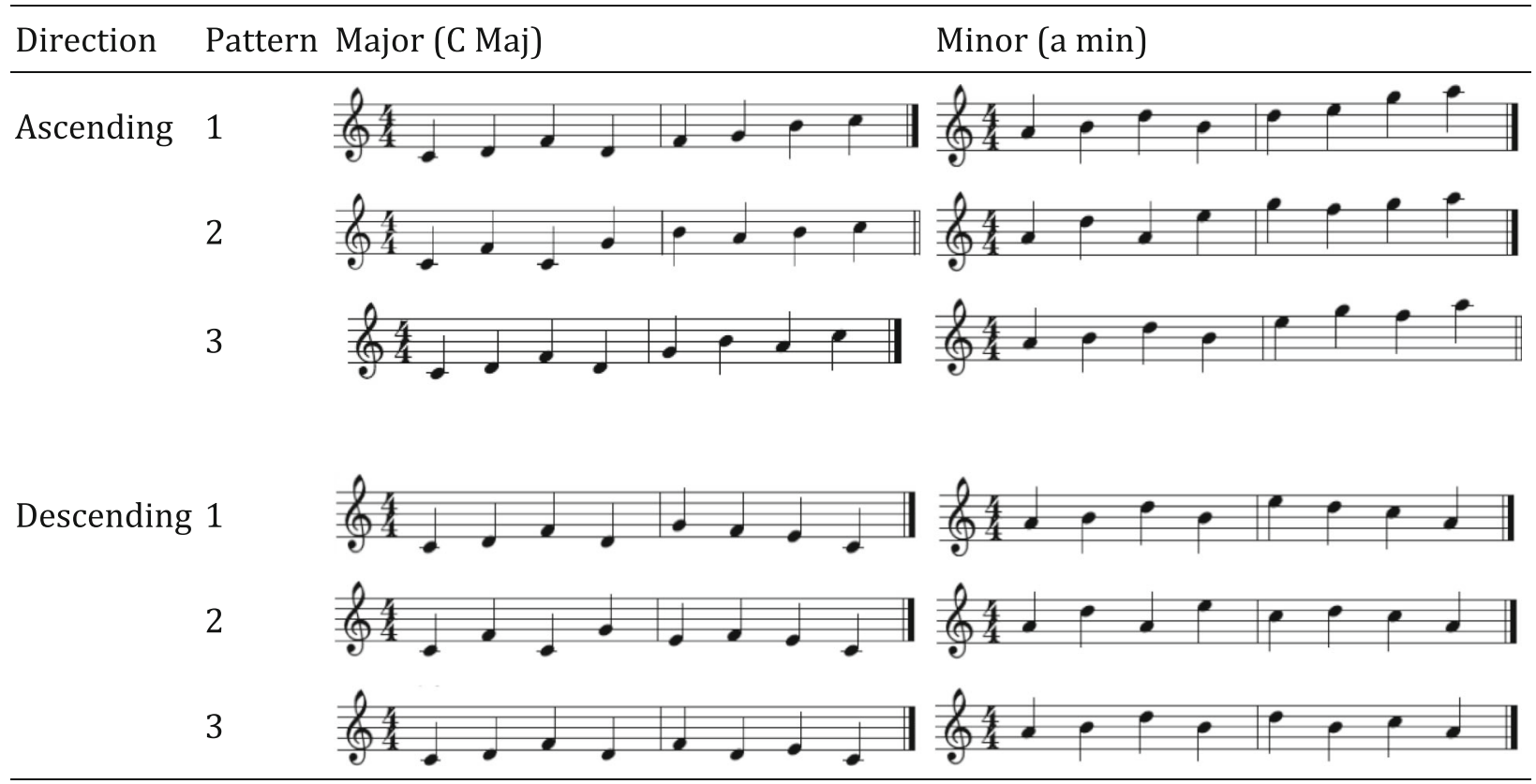

(b) an ascending or descending pitch pattern. The melodies were constructed to be simple, with a definite ascending or descending pattern at the end.

\section{Methods}

Unless described below, all methods were the same as in Experiment 2.

\section{Subjects}

Twenty undergraduate students participated (17 females, 18 right-handed). Subjects ranged in age from 18 to 21 years ( $M$ $=18.45, S D=0.89$ ) and reported normal or corrected-tonormal hearing.

\section{Stimuli and apparatus}

Stimuli included melodies made of eight quarter notes at a tempo of 90 BPM. The first four notes were ambiguous with respect to musical mode as the pitches and intervals could belong to either a major key or its relative minor. The last four notes were played such that the musical mode was either major or minor and ascended or descended in pitch to the final note. During the training phase, Eb-Maj and c-minor were used, and the training phase was the same as in Experiment 2. In the testing phase, the major keys of the melodies included Ab, Bb, C, D, E, F\#, and the relative minor keys included $\mathrm{a}, \mathrm{b}, \mathrm{c \#}, \mathrm{d} \#, \mathrm{f}, \mathrm{g}$. After training, listeners completed one block of 72 mode identification trials (12 keys $\times 2$ pitch directions $\times 3$ melody patterns; see
Table 3). The rating phase consisted of 44 trials with the same major and minor keys as in the testing phase.

\section{Results}

\section{Accuracy}

For each subject, the proportion of correctly identified modes was determined for the ascending and descending versions of each major and minor melody. Mean proportions correct appear in Fig. 1. A 2 (mode: major vs. minor) $\times 2$ (direction: ascending vs. descending) repeated-measures ANOVA revealed a nonsignificant effect of direction, $F(1,19)=3.05, M S E=0.007, p=$ $.097, \eta_{\mathrm{p}}{ }^{2}=0.14$. The effect of mode was significant, $F(1,19)=$ $6.33, M S E=0.010, p=.021, \eta_{\mathrm{p}}{ }^{2}=0.25$, due to a greater proportion of minor melodies correctly identified $(M=0.58 ;[0.52$, $0.63])$ than major melodies $(M=0.52 ;[0.46,0.58])$. The interaction was nonsignificant, $F(1,19)=5.42, M S E=0.108, p=$ $.080, \eta_{\mathrm{p}}{ }^{2}=0.15$, though the crossover pattern was similar to that in Experiment 2. The difference in accuracy for ascending and descending major melodies was not significant $\left(M_{\text {diff }}=0.08\right.$; $[-0.07,0.24]), t(19)=1.09, S E=0.074, p=.290$, whereas accuracy was greater for descending minor melodies than for ascending minor melodies $\left(M_{\text {diff }}=0.19 ;[0.02,0.36]\right), t(19)=$ 2.40, $S E=0.080, p=.026$.

\section{Emotional ratings}

Happiness Major modes $(M=4.51)$ were rated as happier than minor modes $(M=3.48)$, and ascending scales $(M=4.61)$ 
were rated as happier than descending scales $(M=3.38)$. The difference in happiness between major and minor modes was similar for ascending scales $\left(M_{\text {diff }}=1.07 ;[0.50,1.63]\right)$ and descending scales $\left(M_{\text {diff }}=0.98 ;[0.30,1.68]\right)$.

Awkwardness Major modes $(M=3.10)$ were rated as less awkward than minor modes $(M=4.18)$, but the difference in awkwardness between ascending $(M=3.83)$ and descending scales $(M=3.45)$ was not significant. Unlike Experiments 1 and 2, the interaction was not significant, and the difference in awkwardness ratings between major and minor modes was similar for ascending $\left(M_{\text {diff }}=1.22 ;[0.62,1.84]\right)$ and descending scales $\left(M_{\text {diff }}=0.93 ;[0.16,1.70]\right)$.

\section{Sensitivity and response bias}

SDT measures ( $d^{\prime}$ and c) were calculated the same as in Experiment 2, and the average values appear in Table 2. One thing to note is the $d^{\prime}$ values were smaller than Experiment 2, which was likely due to increased difficulty identifying the mode of melodies. Sensitivity $\left(d^{\prime}\right)$ to identifying major modes did not significantly differ between ascending and descending pitch $(p=.084)$. Although the values of $\mathrm{c}$ were in the same directions from zero as in Experiment 2, the difference in $\mathrm{c}$ between ascending and descending pitch was nonsignificant $(p=.061)$

\section{Discussion}

Although the interaction in accuracy did not reach conventional significance, the results of Experiment 3 replicated the crossover pattern from Experiment 2. Specifically, listeners were better at identifying major modes when pitch ascended and better at identifying minor modes when pitch descended. Although the interaction was not statistically significant ( $p=$ .08 ), the crossover pattern suggests the result may be replicable and extend to simple melodies. In Experiment 4, we replicated the procedures used in Experiment 3, but included additional blocks of mode identification trials in order to increase the power to detect the interaction.

\section{Experiment 4}

Experiment 4 was identical to Experiment 3, except listeners completed three blocks of mode identification trials.

\section{Methods}

Unless described below, all methods were the same as in Experiment 3.

\section{Subjects}

Twenty undergraduate students participated (14 females, 17 right-handed). Subjects ranged in age from 18 to 21 years ( $M$ $=18.85, S D=1.14$ ) and reported normal or corrected-tonormal hearing.

\section{Stimuli and apparatus}

Stimuli was the same as Experiment 3, except there were three blocks of 72 trials each in the testing phase.

\section{Results}

\section{Accuracy}

For each subject, the proportion of correctly identified modes was determined for the ascending and descending versions of each major and minor melody. Mean proportions correct appear in Fig. 1. A 2 (mode: major vs. minor) $\times 2$ (direction: ascending vs. descending) repeated-measures ANOVA revealed an effect of mode, $F(1,19)=6.41, M S E=0.014, p=$ $.020, \eta_{\mathrm{p}}{ }^{2}=0.25$, due to a greater proportion of major melodies correctly identified $(M=0.55 ;[0.52,0.58])$ than minor melo$\operatorname{dies}(M=0.48 ;[0.44,0.53])$. The effect of direction was not significant $\left(F=1.62, p=.219, \eta_{\mathrm{p}}{ }^{2}=0.08\right)$. Importantly, the interaction was significant, $F(1,19)=4.64, M S E=0.077, p=$ $\left..044, \eta_{\mathrm{p}}{ }^{2}=0.20\right)$. Accuracy was greater when identifying ascending major melodies than descending major melodies $\left(M_{\text {diff }}=0.20 ;[0.05,0.35]\right), t(19)=2.74, S E=0.073, p=$ .013 , whereas accuracy was greater when identifying descending minor melodies than ascending minor melodies, though the difference was nonsignificant $\left(M_{\text {diff }}=0.07 ;[-0.06,0.20]\right)$, $t(19)=1.11, S E=0.061, p=.279$.

A follow-up repeated-measures ANOVA, with block (1-3) as a factor, revealed a nonsignificant three-way interaction, $F(1,19)=3.04, M S E=0.013, p=.060, \eta_{\mathrm{p}}{ }^{2}=0.14$. As seen in Fig. 2, the crossover pattern was present in each block.

\section{Emotional ratings}

Happiness Major modes $(M=4.39)$ were rated as happier than minor modes $(M=3.50)$, and ascending scales $(M=4.47)$ were rated as happier than descending scales $(M=3.42)$. The interaction was not significant, and the difference in happiness ratings between major and minor modes was similar for ascending scales $\left(M_{\text {diff }}=0.91 ;[0.44,1.37]\right)$ and descending scales $\left(M_{\text {diff }}=0.88 ;[0.33,1.43]\right)$.

Awkwardness Major modes $(M=2.80)$ were rated as less awkward than minor modes $(M=3.60)$. Surprisingly, ascending scales were rated as more awkward $(M=3.35)$ than descending scales $(M=3.55)$. The interaction was not 


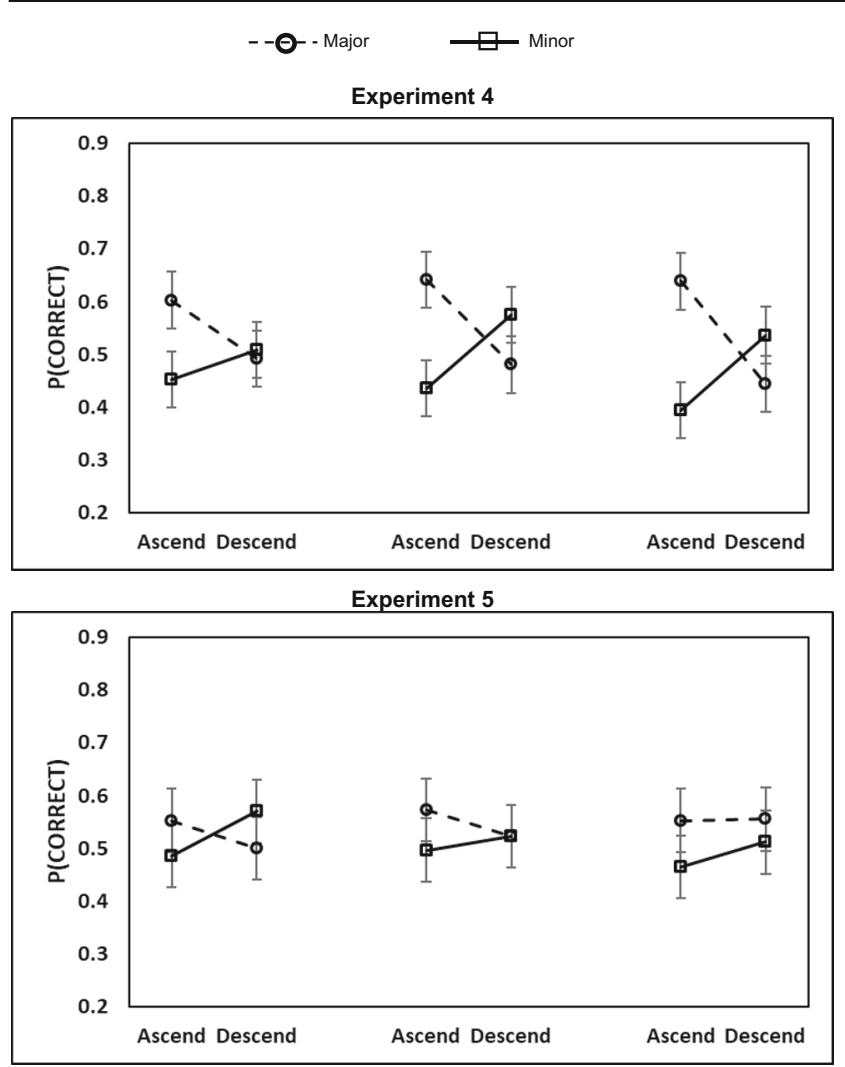

Fig. 2 Mean proportions correct to identify the musical mode (major and minor) of melodies as a function of ascending versus descending pitch and block in Experiments 4 and 5. Error bars are the 95\% confidence intervals based on the within-subjects error term (Equation 2, Hollands \& Jarmasz, 2010)

significant, and the difference in awkwardness between major and minor modes was similar for ascending scales $\left(M_{\text {diff }}=\right.$ $0.75 ;[0.06,1.44])$ and descending scales $\left(M_{\text {diff }}=0.84\right.$; $[0.21,1.47])$.

\section{Sensitivity and response bias}

The SDT measures $\left(d^{\prime}\right.$ and c) were calculated the same as in Experiments 2 and 3, and the average values appear in Table 2. The difference in $d^{\prime}$ between ascending and descending pitch was not significant $(p=.209)$; however, the difference in c was statistically significant $(p=.045)$ and reflects a bias toward selecting 'major' for ascending pitch and a bias toward selecting 'minor' for descending pitch.

\section{Discussion}

Experiment 4 revealed the mode-by-pitch interaction was statistically significant when additional trials were included. This crossover pattern is similar to that observed in Experiments 2 and 3 and was generally present across all three blocks of trials. We made no prediction how the interaction may change across blocks, though one may predict the interaction to attenuate as listeners became familiar with modes, but this was not the case. Additionally, like in Experiment 2, the SDT measures showed no difference in sensitivity $\left(d^{\prime}\right)$, but revealed a bias toward selecting 'major' for ascending scales and a bias toward selecting 'minor' for descending scales. One issue in Experiments 2-4 was that no feedback was provided regarding mode identification accuracy. In Experiment 5, we included feedback to examine whether informing participants of their accuracy would affect performance.

\section{Experiment 5}

In Experiment 5, feedback was provided on each trial to examine whether informing subjects about their accuracy influenced the pitch direction by mode interaction.

\section{Methods}

Unless described below, all methods were the same as in Experiment 4.

\section{Subjects}

Nineteen undergraduate students participated (12 females, 18 right-handed). Subjects ranged in age from 18 to 37 years $(M$ $=20.37, S D=4.15$ ) and reported normal or corrected-tonormal hearing.

\section{Procedures}

All procedures were the same as in Experiment 4, except participants were provided with feedback during the testing phase on every trial. Specifically, if a participant correctly identified the mode, "Correct, this was Major [or Minor]" appeared in green font on the screen. If they responded incorrectly then "Incorrect, this was Major [or Minor]" appeared in red font.

\section{Results}

\section{Accuracy}

For each subject, the proportion of correctly identified modes was determined for the ascending and descending versions of each major and minor melody. Mean proportions correct appear in Fig. 1. Unlike Experiments 2-4, the 2 (mode: major vs. minor) $\times 2$ (direction: ascending vs. descending) repeatedmeasures ANOVA revealed no significant main effects or interaction $\left(F \mathrm{~s}<1.45, p \mathrm{~s}>.244, \eta_{\mathrm{p}}{ }^{2} \mathrm{~s}<0.08\right)$. As seen in Fig. 1, though much less pronounced than in Experiments 2-4, the crossover pattern was present, but again, the interaction was not significant. A repeated-measures ANOVA with 
block (1-3) revealed a nonsignificant three-way interaction $(F$ $<1)$. As seen in Fig. 2, the crossover pattern was present in Block 1, but disappeared in Blocks 2 and 3.

\section{Emotional ratings}

Happiness Major modes $(M=4.26)$ were rated as happier than minor modes $(M=3.83)$, and ascending scales $(M=4.77)$ were rated as happier than descending scales $(M=3.32)$. The difference in happiness between major and minor modes was similar for ascending scales $\left(M_{\text {diff }}=0.40 ;[-0.17,0.98]\right)$ and descending scales $\left(M_{\text {diff }}=0.46 ;[0.02,0.91]\right)$.

Awkwardness Major modes $(M=2.67)$ were rated as less awkward than minor modes $(M=3.70)$, and ascending scales were rated as slightly more awkward $(M=3.30)$ than descending scales $(M=3.07)$. The difference in awkwardness between major and minor keys was similar for ascending scales $\left(M_{\text {diff }}=1.04\right.$; $[0.54,1.55])$ and descending scales $\left(M_{\text {diff }}=1.01 ;[0.46,1.56]\right)$.

\section{Sensitivity and response bias}

The SDT measures ( $d^{\prime}$ and c) were calculated the same as in Experiments 2-4, and the average values appear in Table 2. Neither the difference in $d^{\prime}(p=.502)$ or $\mathrm{c}(p=.399)$ between ascending and descending pitch was statistically significant.

\section{Discussion}

The results of Experiment 5 differed from Experiments 2-4 in that the crossover pattern was present in Fig. 1, but the interaction did not approach significance. Indeed, the crossover was present in Block 1, but absent in Blocks 2 and 3, which may suggest the feedback attenuated or nullified the influence of pitch direction on mode identification.

\section{Experiment 6}

Although Experiment 5 failed to yield a significant direction-by-mode interaction, the crossover pattern that was present across all four experiments suggests that pitch direction has an influence on mode perception. ${ }^{3}$ In Experiment 6, we examined what influence pitch direction alone had on emotional perception and mode perception. As in Experiment 2-5, listeners were

\footnotetext{
${ }^{3}$ It is important to note that the main effect of direction was nonsignificant in Experiments 2-5, and it may be the combination of direction and mode that affects mode identification. In Experiment 6, we examined whether direction - in the absence of mode - had an influence on emotional and mode perception.
}

presented with examples of major and minor ascending and descending scales and also presented with ascending and descending chromatic scales. Following this training phase, subjects were presented with ascending and descending chromatic scales and were asked to rate how (a) sad/happy, (b) dark/bright, (c) awkward, and (d) minor/major each chromatic scale sounded. Thus, Experiment 6 examined how pitch direction alone influenced emotional perception and major/minor mode perception.

\section{Methods}

Unless described below, all methods were the same as in Experiment 1.

\section{Subjects}

Twenty undergraduate students participated (14 females, 19 right-handed). Subjects ranged in age from 18 to 54 years ( $M$ $=23.10, S D=8.94)$ and reported normal or corrected-tonormal hearing.

\section{Stimuli and apparatus}

Instead of eight-note scales played in a major or a minor mode, 13-note chromatic scales were used. All chromatic scales in the $\mathrm{C} 4$ octave range were created in both ascending and descending pitch for 24 total scales.

\section{Procedures}

Each listener was first familiarized with major, minor, and chromatic scales in ascending and descending pitch during the training phase. The C-Maj, a-min, and C-chromatic scales were played 10 times ascending and then 10 times descending, with the order of major, minor, and chromatic counterbalanced across subjects. During the rating phase, only the chromatic scales were used. Each of the 24 chromatic scales was rated on (1) how awkward the scale sounded, (2) how bright/dark the scale sounded, (3) how sad/happy the scale sounded, and (4) how minor/major the scale sounded. All ratings were made on a 7-point scale using the keyboard to respond. Participants completed on block of 96 trials.

\section{Results}

\section{Major-minor ratings}

For each subject, the mean 'minor-major' ratings were determined for the ascending and descending chromatic scales. The mean ratings for ascending and descending chromatic scales appear in Fig. 3, and a paired-samples $t$ test revealed a 


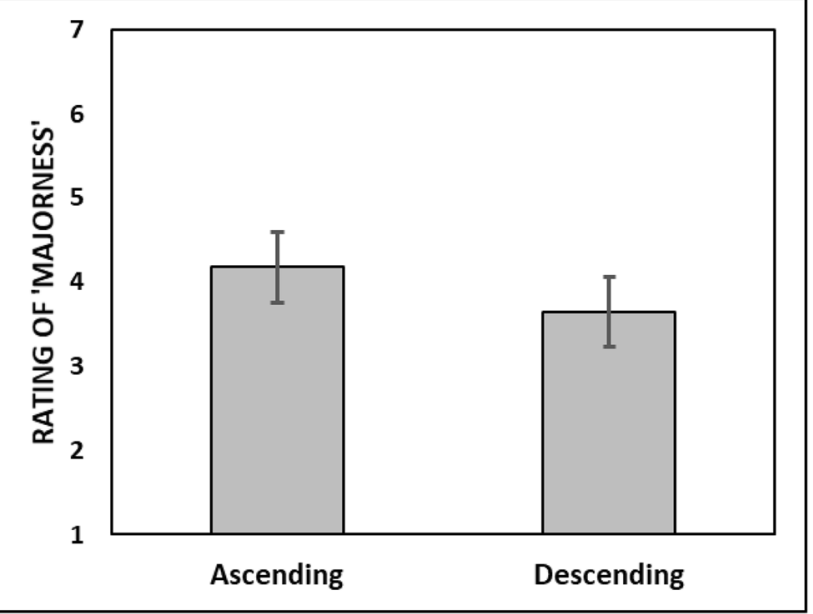

Fig. 3 Mean 'majorness' ratings of ascending and descending chromatic scales. Ratings were made on a 7-point scale, where $1=$ minor and $7=$ major. Error bars are the $95 \%$ CIs

nonsignificant difference in the ratings of 'majorness,' $t(19)=$ $2.03, S E=0.259, p=.057, d_{\text {avg }}=0.59$, with both mean ratings being near the midpoint (4) on the scale.

\section{Emotional ratings}

The results of paired-samples $t$ tests on the ratings appear in Table 4 in Appendix 1. Ascending scales $(M=4.55)$ were rated as happier than descending scales $(M=2.92)$. Ascending scales were also rated as less awkward $(M=$ 3.13) than descending scales $(M=3.34)$, though the difference was not significant. Additionally, ascending scales were rated as brighter $(M=4.78)$ than descending scales $(M=3.20)$.

\section{Discussion}

Experiment 6 examined how pitch direction alone influenced emotional perception and mode perception. The results suggest that when chromatic scales were played ascending, listeners rated them as more major, compared with when chromatic scales were played descending, though this difference was not significant. Additionally, ascending chromatic scales were perceived as more positive (happier, brighter, less awkward) than descending chromatic scales, though the difference was not significant in the awkwardness ratings.

\section{Meta-analysis of Experiments 2-5}

For each pitch direction in Experiments 2-5, the difference in identifying major modes over minor modes was obtained by subtracting the proportion of identified minor modes from the proportion of identified major modes. This difference became the effect size (ES) used in the meta-analysis; hence, positive values indicate a greater accuracy identifying major modes and negative values indicate greater accuracy identifying minor modes.

The unstandardized mean effect sizes $\left(\mathrm{ES}_{\mathrm{u}}\right)^{4}$, standard errors $\left(S E_{\mathrm{u}}\right)^{5}$, and inverse variances $\left(w_{\mathrm{u}}\right)^{6}$ were calculated for ascending and descending pitch (Lipsey \& Wilson, 2001). Standardized effect sizes (Cohen's $d$ ) were not used, because the same measure was used across experiments, sample sizes were similar, and the same participant pool was used. Mean effects sizes $\left(E S_{-}\right)$for ascending and descending pitch were calculated by summing the unstandardized effect sizes $\left(\mathrm{ES}_{\mathrm{u}}\right)$ weighted by the inverse variances $\left(w_{\mathrm{u}}\right)$ and dividing by summed weights. The standard error of the mean effect size $\left(S E_{E S_{-}}\right)$was calculated by taking the square root of the sum of the inverse variances (Lipsey \& Wilson, 2001).

The forest plot in Fig. 4 suggests there was a benefit to identifying major modes for ascending pitch $\left(E S_{-}=0.10 ; C I[0.04,0.16]\right)$, and a benefit to identifying minor modes when pitch was descending $\left(E S_{-}=-0.10 ; C I[-0.16,0.04]\right)$. The effect was significantly different from zero for ascending scales $(z=3.37, S E=0.03, p$ $=.00137)$ and for descending scales $(z=-3.15, S E=0.03, p=$ .00277). The $95 \%$ CIs for the two effects showed no overlap, suggesting the effect sizes for ascending and descending pitch scales significantly different. This was confirmed using a twosample $z$ test to compare the unstandardized mean effect sizes for ascending and descending pitch patterns ${ }^{7}\left(z=4.61, S E_{\text {diff }}\right.$ $=0.04, p=.00000981$ ).

\section{Influence of musical training across Experiments 2-5}

Each subject in each experiment filled out a music experience and training questionnaire prior to completing the auditory task. Table 5 in Appendix 2 presents summary statistics from several items on the questionnaire; in particular, the number of participants in each study who reported (a) music training, (b) taken music lessons, (c) playing an instrument, and (d) having voice training. From the questionnaire, we determined the total number of years of musical experience for each participant, and that mean appears in Table 5 in Appendix 2.

To examine whether musical experience (total years) influenced the results, we combined the musical mode identification results from Experiments 2-5 (see Fig. 5). Next, we ran a 4 (experiment: $2-5) \times 2$ (mode: major vs. minor) $\times 2$

\footnotetext{
$\left.\overline{4}_{E S_{\mathrm{u}}=p(\text { Correct }}\right)_{\text {Major }}-p(\text { Correct })_{\text {Minor }}$

${ }^{5} S E_{u}=\sqrt{\frac{2 S_{p}^{2}(1-r)}{n}}$

${ }^{6} w_{u}=\frac{n}{2 s_{p}^{2}(1-r)}$

${ }^{7} z=\left(\overline{E S}_{A}-\overline{E S}_{D}\right) \frac{-0}{\sqrt{S E_{A}^{2}+S E_{D}^{2}}}$, The 'A' and 'D' subscripts refer to ascending pitch and descending pitch, respectively. The denominator is the standard error of the mean difference.
} 


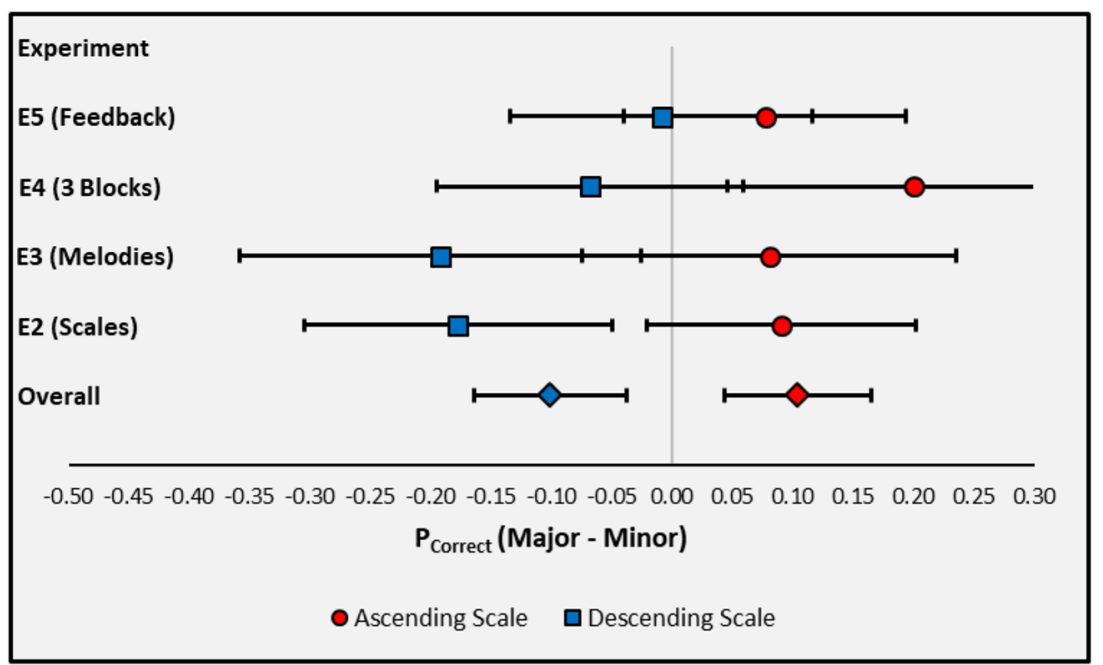

Fig. 4 Forest plot displaying the differences in accuracy for identifying major modes versus minor modes (positive values indicate greater accuracy at identifying major modes), for ascending and descending pitch patterns in Experiments 2-5. Error bars are the 95\% CIs

(direction: ascending vs. descending) mixed-model analysis of covariance (ANCOVA), with total years of musical experience included as the covariate. The results of the ANCOVA appear in Table 6 in Appendix 2 and reveal no relationships with musical experience $(p s>$.327). Importantly, the modeby-direction interaction observed in each experiment was statistically significant $(p<.001)$ and shows the same crossover pattern. In short, it does not appear the influence of pitch direction on mode perception can be attributed to music experience.

\section{General discussion}

This study examined whether pitch direction influenced the identification of mode. Previous studies revealed that major scales and ascending pitch are perceived positively, whereas minor scales and descending pitch are perceived negatively (e.g., Collier \& Hubbard 2001, 2004). Across six experiments, we observed this general pattern in the affective ratings of scales. The more novel result is in the mode identification performance in Experiments 2-5, where we observed that identification of major modes was greater when the scales or melodies ascended in pitch, whereas identification of minor modes was better when scales or melodies descended in pitch. Thus, the combinations of ascending/major and descending/ minor led to better mode identification, but combinations of descending/major and ascending/minor were less accurate. (Though it should, be emphasized that this crossover interaction was statistically significant in only Experiments 2 and 4, and marginally nonsignificant in Experiment 3.)

What is interesting about this result is the crossover pattern held for scales (Experiment 2), simple eight-note melodies without feedback (Experiments 3 \& 4), and with feedback even though that interaction was not significant (Experiment
5). As seen in the meta-analysis across all four experiments (see Fig. 4), it is clear that ascending pitch enhanced identification of major modes and descending pitch enhanced identification of minor modes, suggesting the interaction is replicable and generalized across eight-note scales and simple eightnote melodies.

One thing to note is this study was a bit exploratory in its design and was not intended to assess theories of music perception or why listeners evaluate major and minor modes differently. Specifically, based on research showing major scales and minor scales elicit different affective feelings, that pitch direction is a factor, and observations about pitch direction's influence on perceived musical mode, we hypothesized that mode and pitch direction would interact to influence mode identification, which we observed. The question is why pitch direction influences mode identification. We offer one possible explanation, which will require future research.

It is possible that certain combinations of pitch direction and mode activate the same concept, leading to a clearer perception of mode, whereas certain other combinations of direction and mode activate different concepts, leading to a less clear perception of mode. Specifically, when major modes are combined with ascending pitch, both 'ascending' and 'major' may activate concepts related to 'positivity.' Similarly, when minor modes are combined with descending pitch, both 'descending' and 'minor' may activate concepts related to 'negativity.' In each case, dual activation of those concepts would make it easier to identify the mode. Stated differently, both 'ascending' and 'major' may activate the concept 'positive,' whereas both 'descending' and 'minor' may activate 'negative.' In these cases, the doubly active concept would bias one toward perception of one mode over the other. On the other hand, when major modes are combined with descending pitch, or minor modes are combined with ascending pitch, two different concepts may be activated, making mode 
perception difficult. That is, 'major' may activate 'positive,' while 'descending' activates 'negative,' or 'minor' may activate 'negative,' while 'ascending' activates 'positive,' In these cases, the countervailing activations of 'positive' and 'negative' would render mode perception unclear.

This dual activation hypothesis is beyond the scope of this study and is offered as a possible explanation of the results. Nonetheless, the SDT analyses do shed some insight into the influence that pitch direction had on mode perception. Specifically, across all four experiments, pitch direction showed no influence on the sensitivity $\left(d^{\prime}\right)$ to identify mode; thus, pitch direction may not have affected the ability to accurately identify mode as major or minor. However, in Experiments 2 and 4 and marginally in Experiment 3, pitch direction did bias selection of mode, with ascending pitch biasing the selection of 'major' and descending pitch biasing the selection of 'minor.' The overall pattern of the SDT analyses suggest that pitch direction may not enhance the perceptibility of mode as major or minor. Rather, pitch direction may possibly bias one to perceive mode as major or minor through dual activation of positive or negative concepts.

Future research in our lab is being planned to examine this dual-activation hypothesis as an explanation for the results. Additionally, while the interaction was obtained in three separate experiments using scales and melodies, we are in the process of conducting a high-powered replication of the results observed in Experiment 2. Thirdly, although we did not find musical training to covary with or explain the results, our samples included students who were not music majors (there are no music educational or performance programs at the University of Scranton). As such, we plan to examine whether the crossover remains with musically trained listeners by conducting replications of one or more of the experiments on music majors or professional musicians. Fourth, given that the interaction was observed with simple eight-note melodies, we are planning studies to examine whether this pattern of mode identification emerges when listening to musical pieces with distinct ascending or descending pitch patterns.

\section{Conclusion}

Six experiments examined how combinations of mode and pitch direction influenced mode perception and identification. We found that ascending major modes and descending minor modes were identified better than descending major modes and ascending major modes, suggesting pitch direction affects mode perception (though the interaction reached conventional significance in two of the four experiments). One explanation is that specific combinations of mode and direction facilitate or possibly bias the perception of mode, whereas other combinations attenuate the perception of mode. This will be examined in future studies involving affective priming and signal detection theory.

\section{Appendix 1}

Table 4 Results of the emotional ratings (sad/happy, awkwardness, brightness) analyses in Experiments 1-6

\begin{tabular}{|c|c|c|c|c|c|c|c|}
\hline Exp. & Measure & Effect & $F$ & $d f_{\text {effect }}, d f_{\text {error }}$ & $M S E$ & $p$ & $\eta_{\mathrm{p}}^{2}$ \\
\hline \multirow[t]{9}{*}{1} & \multirow[t]{3}{*}{ Sad/Happy } & Dir (D) & 28.56 & $(1,14)$ & 0.491 & $<.001$ & .67 \\
\hline & & $\operatorname{Mod}(\mathrm{M})$ & 7.38 & $(1,14)$ & 1.606 & .017 & .34 \\
\hline & & D M & 2.86 & $(1,14)$ & 0.234 & .113 & .17 \\
\hline & \multirow[t]{3}{*}{ Awkward } & Dir (D) & 2.35 & $(1,14)$ & 0.734 & .148 & .14 \\
\hline & & Mod (M) & 7.66 & $(1,14)$ & 2.158 & .015 & .35 \\
\hline & & $\mathrm{D} \times \mathrm{M}$ & 5.86 & $(1,14)$ & 0.444 & .030 & .30 \\
\hline & \multirow[t]{3}{*}{ Brightness } & Dir (D) & 42.22 & $(1,14)$ & 0.215 & $<.001$ & .75 \\
\hline & & $\operatorname{Mod}(\mathrm{M})$ & 4.60 & $(1,14)$ & 2.202 & .050 & .25 \\
\hline & & $\mathrm{D} \times \mathrm{M}$ & 3.44 & $(1,14)$ & 0.237 & .085 & .20 \\
\hline \multirow[t]{6}{*}{2} & \multirow[t]{3}{*}{ Sad/Happy } & Dir (D) & 56.42 & $(1,19)$ & 0.372 & $<.001$ & .75 \\
\hline & & $\operatorname{Mod}(\mathrm{M})$ & 21.94 & $(1,19)$ & 1.358 & $<.001$ & .54 \\
\hline & & $\mathrm{D} \times \mathrm{M}$ & 4.23 & $(1,19)$ & 0.123 & .054 & .18 \\
\hline & \multirow[t]{3}{*}{ Awkward } & Dir (D) & 1.62 & $(1,19)$ & 0.353 & .219 & .08 \\
\hline & & $\operatorname{Mod}(\mathrm{M})$ & 17.78 & $(1,19)$ & 0.849 & $<.001$ & .48 \\
\hline & & $\mathrm{D} \times \mathrm{M}$ & 13.18 & $(1,19)$ & 0.182 & .002 & .41 \\
\hline \multirow[t]{6}{*}{3} & \multirow[t]{3}{*}{ Sad/Happy } & $\operatorname{Dir}(\mathrm{D})$ & 27.57 & $(1,19)$ & 1.089 & $<.001$ & .59 \\
\hline & & $\operatorname{Mod}(\mathrm{M})$ & 12.90 & $(1,19)$ & 1.629 & .002 & .40 \\
\hline & & $\mathrm{D} \times \mathrm{M}$ & 0.17 & $(1,19)$ & 0.204 & .685 & .01 \\
\hline & \multirow[t]{3}{*}{ Awkward } & Dir (D) & 2.86 & $(1,19)$ & 1.005 & .107 & .11 \\
\hline & & $\operatorname{Mod}(\mathrm{M})$ & 14.49 & $(1,19)$ & 1.607 & .001 & .43 \\
\hline & & $\mathrm{D} \times \mathrm{M}$ & 0.70 & $(1,19)$ & 0.610 & .414 & .04 \\
\hline \multirow[t]{6}{*}{4} & \multirow[t]{3}{*}{ Sad/Happy } & Dir (D) & 26.90 & $(1,19)$ & 0.826 & $<.001$ & .59 \\
\hline & & $\operatorname{Mod}(\mathrm{M})$ & 17.52 & $(1,19)$ & 0.916 & .001 & .48 \\
\hline & & $\mathrm{D} \times \mathrm{M}$ & 0.01 & $(1,19)$ & 0.268 & .915 & .00 \\
\hline & \multirow[t]{3}{*}{ Awkward } & Dir (D) & 6.73 & $(1,19)$ & 0.275 & .018 & .26 \\
\hline & & Mod (M) & 8.56 & $(1,19)$ & 1.481 & .009 & .31 \\
\hline & & $\mathrm{D} \times \mathrm{M}$ & 0.08 & $(1,19)$ & 0.514 & .778 & .00 \\
\hline \multirow[t]{7}{*}{5} & \multirow[t]{3}{*}{ Sad/Happy } & Dir (D) & 40.10 & $(1,18)$ & 0.999 & $<.001$ & .69 \\
\hline & & $\operatorname{Mod}(\mathrm{M})$ & 4.38 & $(1,18)$ & 0.818 & .051 & .20 \\
\hline & & $\mathrm{D} \times \mathrm{M}$ & 0.06 & $(1,18)$ & 0.310 & .813 & .00 \\
\hline & \multirow[t]{4}{*}{ Awkward } & Dir (D) & 2.20 & $(1,18)$ & 0.486 & .156 & .11 \\
\hline & & Mod (M) & 21.85 & $(1,18)$ & 0.916 & $<.001$ & .55 \\
\hline & & $\mathrm{D} \times \mathrm{M}$ & 0.02 & $(1,18)$ & 0.293 & .889 & .00 \\
\hline & & Effect & $t$ & $d f$ & $S E$ & $p$ & $d_{\mathrm{av}}$ \\
\hline \multirow[t]{3}{*}{6} & Sad/Happy & Dir & 8.30 & 19 & 0.196 & $<.001$ & 2.50 \\
\hline & Awkward & Dir & -1.79 & 19 & 0.118 & .090 & -.21 \\
\hline & Brightness & Dir & 7.11 & 19 & 0.222 & $<.001$ & 2.04 \\
\hline
\end{tabular}

Note. All ratings were made on 7-point Likert scales (see text for details). In Experiments 1-5, ratings were analyzed in 2 (direction: ascending vs. descending $) \times 2$ (mode: major vs. minor) repeated-measures ANOVAS In Experiment 6, ratings were analyzed in paired-samples $t$ tests 


\section{Appendix 2}

This section reports summary statistics form the music experience questionnaire that was completed by each participant, and accompanying ANCOVA results as described in the main text.

Table 5 Select descriptive statistics from the music experience and demographics questionnaire

\begin{tabular}{|c|c|c|c|c|c|c|c|}
\hline \multirow[t]{2}{*}{ Exp. } & \multirow[t]{2}{*}{$N$} & \multicolumn{4}{|c|}{ Number of subjects reporting: } & \multicolumn{2}{|c|}{ Years of musical experience } \\
\hline & & Music training & Taking lessons & Playing an instrument & Vocal training & $M$ & $S D$ \\
\hline 1 & 15 & 9 & 10 & 12 & 2 & 10.23 & 10.37 \\
\hline 2 & 20 & 8 & 9 & 15 & 5 & 8.10 & 9.84 \\
\hline 3 & 20 & 11 & 10 & 16 & 6 & 8.34 & 8.24 \\
\hline 4 & 20 & 5 & 5 & 13 & 4 & 5.68 & 6.06 \\
\hline 5 & 19 & 5 & 7 & 10 & 4 & 5.32 & 7.94 \\
\hline
\end{tabular}

Table 6 Results of a mixed-model ANCOVA on the mode identification accuracies across Experiments 2-5

\begin{tabular}{|c|c|c|c|c|c|}
\hline Effect & $F$ & $\left(d f_{\text {effect }}, d f_{\text {error }}\right)$ & $M S E$ & $p$ & $\eta_{\mathrm{p}}^{2}$ \\
\hline Experiment & 6.43 & 3,73 & 0.067 & .001 & .21 \\
\hline Mode & $<1.00$ & 1,73 & 0.140 & .976 & $<.01$ \\
\hline Mode $\times$ Years & $<1.00$ & 1,73 & 0.140 & .999 & $<.01$ \\
\hline Mode $\times$ Experiment & 4.83 & 3,73 & 0.140 & .004 & .17 \\
\hline Direction & $<1.00$ & 1,73 & 0.009 & .472 & .01 \\
\hline Direction $\times$ Years & $<1.00$ & 1,73 & 0.009 & .327 & .01 \\
\hline Direction $\times$ Experiment & 3.79 & 3,73 & 0.009 & .013 & .14 \\
\hline Mode $\times$ Direction & 14.21 & 1,73 & 0.071 & $<.001$ & .16 \\
\hline Mode $\times$ Direction $\times$ Years & $<1.00$ & 1,73 & 0.071 & .589 & $<.01$ \\
\hline Mode $\times$ Direction $\times$ Experiment & $<1.00$ & 3,73 & 0.071 & .588 & .03 \\
\hline
\end{tabular}

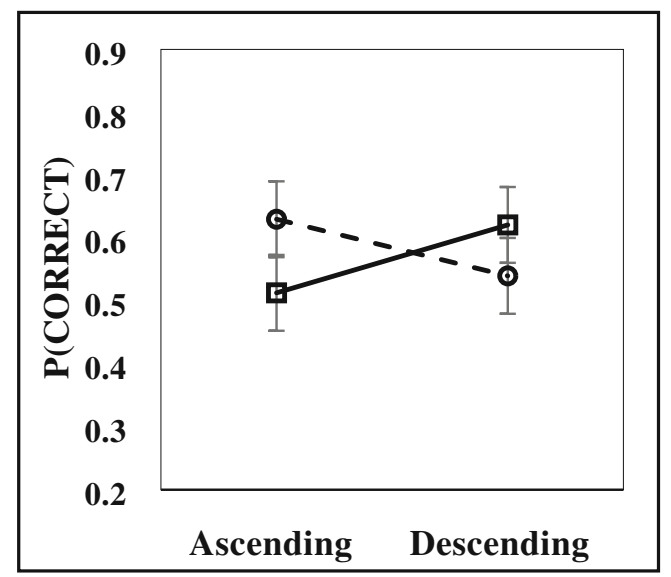

Fig. 5 Mean proportions correct to identify the musical mode of scales (Experiment 2) and melodies (Experiment 3-5) as a function of ascending versus descending pitch, combined over all experiments. Error bars are the $95 \%$ confidence intervals based on the within-subjects error term (Equation 2, Hollands \& Jarmasz, 2010) 


\section{References}

Battcock, A., \& Schultz, M. (2019). Acoustically expressing affect. Music Perception, 37(1), 66-91. https://doi.org/10.1525/mp.2019. 37.1.66

Blechner, M. J. (1977). Musical skill and the categorical perception of harmonic mode Haskins Laboratories status report on speech perception (SR-51/52, pp. 139-174). New Haven, CT: Haskins Laboratories.

Burns, E. M., \& Ward, W. D. (1982). Intervals, scales, and tuning. In D. Deutsch (Ed.), The psychology of music (pp. 431-451). New York, NY: Academic Press.

Collier, W. G., \& Hubbard, T. L. (2001). Musical scales and evaluations of happiness and awkwardness: Effects of pitch, direction, and scale mode. The American Journal of Psychology, 114(3), 355-375. https://doi.org/10.2307/1423686

Collier, W. G., \& Hubbard, T. L. (2004). Musical scales and brightness evaluations: Effects of pitch, direction, and scale mode. Musicae Scientiae, 8(2), 151-173. https://doi.org/10.1177/ 102986490400800203

Crowder, R. G. (1984). Perception of the major/minor distinction: I. Historical and theoretical foundations. Psychomusicology, 4(1/2), 3-12. https://doi.org/10.1037/h0094207

Crowder, R. G. (1985). Perception of the major/minor distinction: II. Experimental investigations. Psychomusicology, 5(1/2), 3-24. https://doi.org/10.1037/h0094203

Dalla Bella, S., Peretz, I., Rousseau, L., \& Gosselin, N. (2001). A developmental study of the affective value of tempo and mode in music. Cognition, 80, B1-B10. https://doi.org/10.1016/S0010-0277(00) 00136-0

Egmond, R., \& Boswijk, M. (2007). The perception of key: The role of music training. Music Perception, 25(1), 31-42. https://doi.org/10. 1525/MP.2007.25.1.31

Friedman, R. S., Neill, W. T., Seror, G. A., III, \& Kleinsmith, A. L. (2018). Average pitch height and perceived emotional expression within an unconventional tuning system. Music Perception, 35(4), 518-523. https://doi.org/10.1525/MP.2018.35.4.518

Gerardi, G. M., \& Gerken, L. (1995). The development of affective responses to modality and melodic contour. Music Perception, 12(3), 279-290. https://doi.org/10.2307/40286184

Green, D. M., \& Swets, J. A. (1966). Signal detection theory and psychophysics. New York, NY: Wiley.

Gregory, A. H., Worrall, L., \& Sarge, A. (1996). The development of emotional responses to music in young children. Motivation and Emotion, 20(4), 341-348. https://doi.org/10.1007/BF02856522

Heinlein, C. P. (1928). The affective characteristics of the major and minor modes. Journal of Comparative Psychology, 8, 101-142. Retrieved from https://www.jstor.org/stable/1416710

Hevner, K. (1935). The affective character of the major and minor modes in music. American Journal of Psychology, 47, 103-118. https://doi. org/10.2307/1416710

Hollands, J. G., \& Jarmasz, J. (2010). Revisiting confidence intervals for repeated measures designs. Psychonomic Bulletin \& Review, 17(1), $135-138$.

Husain, G., Thompson, W. F., \& Schellenberg, E. G. (2002). Effects of musical tempo and mode on arousal, mood, and spatial abilities. Music Perception, 20(2), 151-171. https://doi.org/10.1525/mp. 2002.20.2.151
Johnson-Laird, P. N., Kang, O. E., \& Leong, Y. C. (2012). On musical dissonance. Music Perception, 30(1), 19-35. https://doi.org/10. 1525/MP.2012.30.1.19

Justus, T., Gabriel, L., \& Pfaff, A. (2018). Form and meaning in music: Revisiting the affective character of the major and minor modes. Auditory Perception \& Cognition, 1(3/4), 229-247. https://doi.org/ 10.1080/25742442.2019.1597578

Kastner, M. P., \& Crowder, R. G. (1990). Perception of the major/minor distinction: IV. Emotional connotations in young children. Music Perception: An Interdisciplinary Journal, 8(2), 189-201. https:// doi.org/10.2307/40285496

Kleinsmith, A. L., Friedman, R. S., \& Neill, W. T. (2017). Reinvestigating the impact of final ritardandi on music evaluation and felt musical tension. Psychomusicology: Music, Mind, and Brain, 27(4), 267-280. https://doi.org/10.1037/pmu0000195

Lee, Y.-S., Janata, P., Frost, C., Hanke, M., \& Granger, R. (2011). Investigation of countour processing in the brain using multivariate pattern-based fMRI. NeuroImage, 57, 293-300. https://doi.org/10. 1016/jneuroimage.2011.02.006

Lipsey, M. W., \& Wilson, D. B. (2001). Practical meta-analysis. Thousand Oaks, CA: SAGE Publications.

Macmillan, N. A., \& Creelman, C. D. (2005). Detection theory: A user's guide (2nd ed.). Mahwah, NJ: Erlbaum.

McLachlan, N., Marco, D., Light, M., \& Wilson, S. (2013). Consonance and pitch. Journal of Experimental Psychology: General, 142(4), 1142-1158. https://doi.org/10.1037/a0030830

Mead, K. M. L., \& Ball, L. J. (2007). Music tonality and contextdependent recall: The influence of key change and mood mediation. European Journal of Cognitive Psychology, 19(1), 59-79. https:// doi.org/10.1080/09541440600591999

Parncutt, R. (2014). The emotional connotations of major versus minor tonality: One or more origins? Musicae Scientiae, 18(3), 324-353. https://doi.org/10.1177/1029864914542842

Sollberger, B., Reber, R., \& Eckstein, D. (2003). Musical chords as affective priming context in a word evaluation task. Music Perception, 20(3), 263-282. https://doi.org/10.1525/mp.2003.20.3.263

Thompson, W. F., \& Cuddy, L. L. (1997). Music performance and the perception of key. Journal of Experimental Psychology: Human Perception and Performance, 23(1), 116-135. https://doi.org/10. 1037/0096-1523.23.1.116

Trehub, S. E. (1993). The music listening skills of infants and young children. In T. J. Tighe \& W. J. Dowling (Eds.), Cognitive bases of musical communication. Washington, DC: American Psychological Association.

Zatorre, R. J., \& Halpern, A. R. (1979). Identification, discrimination, and selective adaptation of simultaneous musical intervals. Perception \& Psychophysics, 26, 384-395. https://doi.org/10.3758/BF03204164

Open practices statement None of the experiments reported in this study was preregistered; however, data or materials used to run the experiments will be made available upon request.

Publisher's note Springer Nature remains neutral with regard to jurisdictional claims in published maps and institutional affiliations. 